\title{
Applying Student Development Theories: Enhancing International Student Academic Success and Integration
}

\author{
Anduena Ballo ${ }^{\mathrm{a} *}$, Charles Mathies ${ }^{\mathrm{b}}$, Leasa Weimer ${ }^{\mathrm{b}}$ \\ ${ }^{\mathrm{a}}$ Faculty of Education, University of Jyväskylä, Finland; ${ }^{\mathrm{b}}$ Finnish Institute for Educational Research, University of \\ Jyväskylä, Finland \\ *Corresponding author: Email: anduena.b@outlook.it \\ Address: Faculty of Education, PO Box 35, University of Jyväskylä, FIN-40014
}

\section{Introduction}

The student body in many higher education institutions (HEIs) has become more international, although student services are often offered in a generic one-size fits all approach (Manning, Kinzie, and Schuh 2014). However, international students represent a heterogeneous community (Jones 2017; O'Conner 2018) who often lack the local social and cultural capital domestic students embody (particularly language skills). Jones (2017) argues that HEIs should not differentiate between domestic and international students in assessing needs and services provided, but this is problematic as international students have specific needs and require targeted services, in addition to the ones provided to domestic students (Marginson 2010). Traditionally, student services served as a key indicator of student satisfaction and influenced the mobility of international students' choices regarding study programme, HEI, and country of study (van der Beek and van Aart 2014). However, recent research shows that student services are becoming less important in these regards (Amigan and Jones 2018). Most services offered to international students relate to the student academic experience. As Perez-Encinas and Rodriguez-Pomeda (2018) demonstrate with European exchange students, academic services are not enough; services related to the student living experiences (e.g. accommodations, cultural and social activities, etc.) and comfort (e.g. student employment/living expenses, security, etc.) are also needed to improve the international student experience.

In this paper we focus on Student Development Theories (SDT) as a way to increase our understanding of how to improve international students' academic success and integration. SDT has long been the theoretical foundation for student services in North America. While there are frameworks in other parts of the world (e.g. students as partners) containing similar elements, we contend SDT is substantially different because as a theoretical framework it acknowledges how students develop holistically, as well as what factors and environmental conditions can facilitate their development (Evans, Forney, Guido, Patton, and Renn 2010). While debates occur over how theory can translate into practice, there is a common understanding among practitioners that SDT provides at minimum "guiding concepts" to explicitly direct the development of student services (Reason and Kimball 2012, p. 360). We argue using SDT as a framework can provide a developmental and holistic approach to international student services. More specifically, we present models viewing student development from the multiple domains, all of which tailor programmes designed for student success, and social and academic integration.

A student's integration is a multi-dimensional concept involving social, economic, political and cultural considerations, and it is difficult to measure and evaluate (Rytter 2018). Strange (2010) argues social and academic integration represents the extent to which a student is satisfied with the campus' social and cultural environment, and attainment of personal educational objectives or acquisition of desired skills and competences. It has been suggested students' social and academic integration influences subsequent commitment to the HEI and degree completion (Hirschy 2016). Specifically, the formal and informal interactions between international students and HEI community 
members (domestic students and academic staff) on academic issues, language support, social activities, and career guidance promote higher levels of integration into a host country (Kelo, Rogers, and Rumbley 2010; Hirschy 2016).

We focus both on credit and degree mobile students in this paper. While there are differences between both groups, there are also a number of commonalities (King, Findlay, and Ahrens 2010), including their need for services (academic, living, and comfort/security) while they study abroad. After all, all international students need the support, information, and activities these services provide. For example, many HEIs focus on degree-mobile students rather than credit-mobile students with their career or guidance services; degree-mobile students are considered "their" students while credit-mobile students are more likely to be considered "visitors". However, if an HEI accepts an international student, regardless if they are degree-or credit-mobile, they have a duty and responsibility to educate and support that student, including the provision of services supporting students to meet their career goals.

\section{Overview of Student Development Theory}

The literature on SDT provides explanations of student development and assists in understanding the process and substance of students' experiences intersecting with various aspects of an HEI's environment, student services and organizational structures (Schuh, Jones, and Torres 2016). SDTs provide lenses through which to view, understand and support students' development occurring while they are in higher education (Jones and Abes 2016). Psychosocial and cognitive-structural theories are considered fundamental to understand student development, though new "theoretical frameworks" have emerged interpreting the interaction of the student development process, content and context in higher education (Jones and Abes 2016). For example, environmental theories, acknowledge the importance of campus environment for shaping students' experience, learning outcomes and development in post-secondary education (Astin 1984; Museus 2014) while the more recent holistic perspective (Baxter Magolda 2009) brings together cognitive, interpersonal and intrapersonal dimensions to understand how students achieve self-authorship to meet life's challenges and be successful in adult life.

\section{Focusing in on Three Models of Student Development}

A number of models of student development derive from the foundational SDTs and "new approaches" offering useful frameworks for practical applications. Due to the space limitations, we focus on three models that in our view could have significant influence on international student success and integration.

First, the Learning Partnerships Model (LPM) emerged from a longitudinal study of adult development examining self-authorship and learning in different contexts, including multiple student populations, educational contexts, and curricular and co-curricular activities (Baxter Magolda 2004). According to Baxter Magolda (2001, p. xvi), selfauthorship is "the capacity to internally define own beliefs, identity and relationships". The journey toward selfauthorship begins with students trusting external authorities for knowing the world and themselves (Baxter Magolda 2001). Dissonance with external authorities brings them to a crossroad where they are challenged to rely on their internal sense of self rather than following others' visions and expectations (Baxter Magolda 2001). By listening and cultivating their internal voice, they build an internal belief system and shift toward self-authorship (Baxter Magolda 2001). Identifying conditions that promote self-authorship, the LPM model assumes that learners' self-authorship journey is challenged by three principles: validating capacity of learners as knowledge constructors, situating learning in learners' experiences, and defining learning as mutually constructing meaning (Baxter Magolda 2004). These three principles are key in creating intentional learning partnerships encouraging students to bring their own experiences into the classroom, exchange their ideas with peers and teachers and participate in social knowledge construction (Baxter Magolda 2004). In short, students feel supported when their thoughts and feelings are respected, and when they are encouraged to handle their experiences and solve problems in a collaborative environment (Baxter Magolda 2004). 
Second, Samuel Museus's (2014) Culturally Engaging Campus Environments (CECE) model accounts for the climate, culture, and organizational elements of a HEI. This in turn explains and helps the understanding of the impact of institutional environments on the outcomes of diverse student populations. The CECE model emphasises the role and the responsibility of HEIs in constructing environments that shape students' experiences and success (Museus 2014). The central points of this model, derived from a longitudinal qualitative study, are indicators of cultural relevance (cultural familiarity, cultural knowledge, community services, cross-cultural engagement, cultural validation) and cultural responsiveness (collectivist orientations, humanized environments, proactive philosophies and holistic support) that engage students' multiracial cultural backgrounds and identities, reflect their diverse needs, and facilitates their success in higher education (Museus 2014). These indicators mainly focus on the extent to which campus learning and support systems respond to the cultural norms and needs of culturally diverse students (Museus and Smith 2016). The CECE model suggests that when students have opportunities to connect with staff and peers, it permits them to share common backgrounds (Museus 2014). Maintaining connections based on culture origins and active participation in activities and projects relevant to their cultural communities allows for meaningful cross-cultural interactions which validates their cultural identities and leads them to succeed in higher education (Museus 2014; Museus and Smith 2016). The CECE model also acknowledges that different external factors such as finances, employment and family support influence student experiences and shapes their success in higher education (Museus 2014).

The third model is the "transitions" model originating from Schlossberg, Waters and Goodman's transition theory (1995). It is an "eclectic theory looking at context, development and life span" and is a useful framework explaining adult behaviours when coping with life situations, events and change. It defines a transition as "any event or non-event that results in change of relationships, routines, assumption and roles" (Schlossberg, Waters, and Goodman 1995, p. 27). However, Goodman, Schlossberg, and Anderson (2006) argue that any transition (event or non-event) needs defining by the person experiencing it and results in a change of person's behaviour. The model has three major components. Approaching a transition identifies the change and the degree to which it is causing changing reactions in persons' life over time. The taking stock introduces the four S's: situation, self, support and strategies that provide ways to identify potential resources for someone to cope with transitions. Taking charge occurs when new strategies are utilised to deal with different phases of the transition. This model helps explain how individuals react differently to life transitions (Schlossberg, Waters, and Goodman 1995). Students moving into a new situation need to become familiar with rules and expectations of the educational environment and feel supported and challenged during their journey in order to move into the next phase of the transition (Anderson, Goodman, and Schlossberg 2012). These models considering different aspects of holistic student development such as, preparing to become successful adults in life, the importance of culturally diverse campus environments in shaping their experience, and understanding how development occurs during transitions are useful frameworks to consider when designing services needed in each phase of their higher education journey.

\section{Discussion}

Perez-Encinas and Rodriquez-Pomeda (2018) group international student services into four stages of international students' life cycle (pre-arrival, arrival, during stay, and re-integration [in their home country or in a third country] after their stay abroad) and is valuable in discussing the intersections between SDT and International Student Mobility and Migration (ISM). ISM is conceptualised as a dynamic process where an individual student's agency is simultaneously constrained and enabled by external factors such as governmental or institutional policy, family considerations and labour market opportunities (Mosneaga and Winther, 2013; Van Mol 2014). In particular, governmental and HEI policy shape international students' motivations to move across borders for education 
(Raghuram 2013). Riaño, Van Mol, and Raghuram (2018) argue there are five distinct types (economic agents, sources of income for higher education, temporary subjects, immigrates of doubtful value, and part of soft power) of policy discourses within ISM; each influencing ISM differently. While most ISM-policy discussions are focused at governmental or national level (Raghuram, 2013; Riaño, Van Mol, and Raghuram 2018), discussions on HEI or local ISM-policy are important as these policies are particularly impactful on international students' lived day-to-day experiences and integration to the local host academic and social communities (O'Connor 2018).

In the pre-arrival stage, the primary focus of services is on academic (e.g. application and programme) and environmental (e.g. where to live, visa/entry requirements, etc.) information for students. In this stage, international students transition to the idea of living and studying abroad seeking information to make informed decisions. Schlossberg, Waters, and Goodman (1995) "transition" model suggests practitioners should support this by providing as much personalized information and communication as needed. Pre-arrival information tailored to either a specific location and/or unique circumstances delivered in a personalized and meaningful manner increases the likelihood students will experience a successful international study period (Kelo, Rogers, and Rumbley 2010). Questions practitioners should consider include "what information is desired?" and "what information is needed?" by international students. The aim is to assist international students in understanding the context (academic programme, and location) and prepare for the transition they are about to make (Anderson, Goodman, and Schlossberg 2012).

During the arrival stage, most services focus on orientation, integration with the local community (with local students as well as integration into the locality), and providing non-academic information, for example, security, cultural and social activities, often including the locations of restaurants, libraries, and medical services. Schlossberg, Waters, and Goodman (1995) "transitions" model suggests practitioners should examine the support they provide as this is when international students begin to transition through a culture shock (Zhou, Jindal-Snape, Topping, and Todman 2008) and its accompanying phases. Tools like a self-assessment interview guide could be used as part of the orientation activities to encourage deep reflection about students' experiences, helping them identify their interests and needs in developing their 'internal voice' (Baxter Magolda 2004), and the subsequent related services. Anderson, Goodman, and Schlossberg (2012) suggest assessment strategies could help students understand the transition(s) they are experiencing; examples include a worksheet to identify each four-S's with listings under each important aspect for the individual's reflection and discussion. Lastly, the "transitions" model suggests that practitioners and HEIs (as organisations) need to be proactive and reach out to students repeatedly and through different mediums (emails, flyers, sponsored events, social media, etc.) during this stage; they cannot assume international students will come to them with questions and concerns.

The third stage, during students' stay, is usually the longest (in duration) and most services here focus on academic support (e.g. writing and language services), health and well-being (physical and mental), and fostering and maintaining local social networks through informal and formal activities. Museus' CECE model (2016) suggests HEIs examine how their environment shapes international students' experiences and success, as well as their sense of belonging in the HEI community by nurturing cross-cultural interactions. This approach advocates HEIs offering programs and practices that facilitate educational and meaningful opportunities for intercultural exchange, among international students as well as with domestic students. Baxter Magolda's (2001, 2004) LPM model suggests HEIs examine how their students construct relationships with peers, teachers, and within the local community. Practitioners ought to ask the question "what services exist to encourage international students to be involved in the academic and the local community?"

The last stage, integration and re-integration, involves two aspects. Integration into the host country includes the students' ability to establish a life and enter the labour market. On the other hand, re-integration relates to the return of students back into their host country or onto a third country post studies and preparing students for reverse culture shock if they return home. For both aspects, student services should focus on student completion and career services with a particular emphasis on employability. These services ought to offer structured opportunities for students to 
engage in internship programmes, service learning or other work experience (Hamrick, Evans, and Schuh 2002). Baxter Magolda (2001) points out benefits of an internship or part time-job in developing self-authorship including opportunities to assume responsibility, encourage decision-making, and taking risks. The LPM model argues that selfauthorship allows "the capacity to internally define a coherent belief system and identity that coordinates engagement in mutual relations with the larger world" (Baxter Magolda 2004, p. xxii). Additionally, Astin (1993) contends parttime work off campus is positively associated with academic performance and achievements such as completing a degree. Practitioners and professors can work together to develop programmes such as research assistantships, course projects, service-learning courses connected to specific occupations and work opportunities which enhance students' working experience and their social and academic integration.

\section{Conclusion}

In this article, we presented a first step bringing the literatures of SDT and ISM together. More work needs to be done, but as we demonstrate, SDT can potentially be a valuable tool in developing international student services that positively influence international students' success and integration. International students, regardless if they are degree or credit mobile, are heterogeneous not only in their backgrounds (academic preparation, nationality, culturally, etc.) but also in their personal development (Perez-Encinas and Rodriquez-Pomeda 2018). As such, students from similar backgrounds and/or in the same life cycle will have different student service needs.

It is worth noting some critiques of SDT models as they relate to the development of international student services. For example, SDT has been criticised for primarily focusing on North American domestic students, and often minimizes or excludes non-white and non-North American student experiences. However, research shows SDT models promote culturally engaging campus environments that are positively associated with high levels of engagement and academic performance, increased motivation and sense of belonging; ultimately, greater student success (Museus 2014). This suggests care and attention is required to ensure the interests and needs of international students are served when SDT models are used as frameworks in developing international student services.

Being intentional about designing international student services has its benefits. Drawing from STD helps to frame programmatic innovations, inform classroom teaching and develop holistic services. As HEIs continue to evolve in their internationalisation efforts, they must offer opportunities and support for international students to be academically successful and to integrate into the local community. It is clear more work is needed with SDT and international students, particularly when considering ISM's proposing students' agency can be simultaneously constrained or enabled by external factors such governmental or HEI policy. We hope this paper could serve as a starting point to further elaborate on an integration of these frameworks as we feel using SDT models in developing international student services considers the holistic development of students promoting an inclusive internationalisation effort, which likely creates a welcoming and supportive environment shaping the international students' experiences.

\section{References}

Anderson, Mary, Jane Goodman, and Nancy Schlossberg. 2012. Counseling Adults in Transition. New York: Springer Publishing Comapany.

Astin, Alexander. 1984. "Student Involvement: A Development Theory for Higher Education Student Involvement: A Developmental Theory for Higher Education.” Journal of College Student Development, 40 (5): 518-529.

Astin, Alexander. 1993. What Matters in College? Four Critical Years Revisited. San Francisco: Jossey-Bass. Baxter Magolda, Marcia. 2001. Making Their Own Way. Sterling, Virginia: Stylys. 
Baxter Magolda, Marcia. 2009. Authoring Your Life: Developing an Internal Voice to Navigate Life's Challenges. Sterling, Virginia: Stylys.

Baxter Magolda, Marcia. 2004. "Learning Partnerships Model" In Learning Partnerships Theory and Models of Practice To Educate for Self Authorship, edited by Marcia Baxter Magolda and Patricia King, 37-62. Sterling, Virginia: Stylys.

Evans, Nancy, Deanna Forney, Florence Guido, Lori Patton, and Kristen Renn. 2010. Student Development in College: Theory, Research, and Practice . San Francisco: Jossey-Bass.

Hamrick, Florence, Nancy Evans, and John Schuh. 2002. Foundations of Student Affairs Practice. San Francisco: Jossey-Bass

Hirschy, Amy. 2016. "Student Retention and Institutional Success". In Student Services: A Handbook for the Profession, edited by John Schuh, Susan Jones and Vasti Torres. 252-267. San Francisco: Jossey-Bass.

Jones, Elspeth. 2017. "Problematising and Reimaging the Notion of 'International Student Experience'." Studies in Higher Education 42(5): 933-943.

Jones, Susan and Elisa Abes. 2016. "The Nature and Uses of Theory." In Student Services: A Handbook for the Profession edited by John Schuh, Susan Jones and Vasti Torres. 137-152. San Francisco: Jossey-Bass.

Kelo, Maria, Tim Rogers, and Laura Rumbley. 2010. International Student Support in European Higher Education: Needs, Solutions, Challenges. Bonn: Lemmens Medien GmbH.

King, Russell, Allan Findlay, and Jill Ahrens (2010). International Student Mobility Literature Review. Bristol: Higher Education Funding Council for England.

Manning, Kathleen, Jillian Kinzie, and John Schuh. 2014. One Size Does Not Fit All: Traditional and Inovative Models of Student Affairs Practice. New York: Routledge.

Marginson, Simon. 2010. "Here's How We Can End the Threats to International Students". Chronicle of Higher Education. Retrieved from: https://www.chronicle.com/article/International-Students-Are-at/66051

Mosneaga, Ana and Lars Winther. 2013. "Emerging Talents? International Students Before and After Their Career Start in Denmark". Population, Space, and Place 19: 181-195.

Museus, Samuel. 2014. "The Culturally Engaging Campus Environments (CECE) Model: A New Theory of College Success Among Racially Diverse Student Populations". In Higher Education: Handbook of Theory and Research, edited by Michael Paulsen, 189-227. New York: Springer

Museus, Samuel and Edward Smith. 2016. The Culturally Engaging Campus Environments Model and Survey. Washington DC: NASPA. https://www.naspa.org/rpi/reports/cece-project

O’Connor, Sinéad. 2018. "Problematising Strategic Internationalisation: Tensions and Conflicts Between International Student Recruitment and Integration Policy in Ireland." Globalisation, Societies and Education 16(2): 339-352.

Perez-Encinas, Adriana, and Jesus Rodriguez-Pomeda. 2018. "International Students' Perceptions of Their Needs When Going Abroad: Services on Demand". Journal of Studies in International Education 22(1): 20-36.

Raghuram, Parvati. 2013. “Theorising the Spaces of Student Migration”. Population, Space, and Place. 19: 138-154.

Reason, Robert and Ezekiel Kimball. 2012. "A New Theory-To-Practice Model for Student Affairs: Integrating Scholarship, Context, and Reflection.” Journal of Student Affairs Research and Practice 49(4): 359-376.

Riaño, Yvonne, Christof Van Mol, and Parvarti Raghuram. 2018. "New Directions in Studying Policies of International Student Mobility and Migration”. Globalisation, Societies and Education 16(3): 283-294.

Rytter, Mikkel. 2018. "Writing Against Integration: Danish Imaginaries of Culture, Race and Belonging." Ethnos 0(0). Taylor \& Francis: 1-20.

Schlossberg, Nancy, Elinor Waters, and Jane Goodman. 1995. Counseling Adults in Transition. New York, NY: Springer.

Schuh, John, Susan Jones and Vasti Torres. 2016. Student Services: A Handbook for the Profession. San Francisco: Jossey-Bass. 
Strange, Carney. 2010. "Theoretical Foundations of Student Success". In Achieving Student Success, edited by Donna Hardy Cox and Carney Strange, 18- 29. McGill-Queen's University Press.

Van der Beek, Charline and Joran van Aart. 2014. Key Influencers of International Student Satisfaction in Europe. Eindhoven, Netherland: Study Portals.

Van Mol, Christof. 2014. Intra-European Student Mobility in International Higher Education Circuits: Europe on the Move. Basingstoke: Palgrave Macmillan.

Zhou, Yuefang, Divya Jindal-Snape, Keith Topping, and John Todman. 2008. "Theoretical Models of Culture Shock and Adaptation in International Students in Higher Education.” Studies in Higher Education 33(1): 63-75. 